\title{
Cultural aspects in dementia: differences in the awareness of Brazilian caregivers
}

\author{
Aspectos culturais na demência: \\ diferenças na consciência da doença de cuidadores brasileiros
}

Raquel L. Santos, Maria F. B. de Sousa, Ana C. Ganem, Thais V. Silva, Marcia C. N. Dourado*

\begin{abstract}
Objective: To explore differences in disease awareness in participants of a psychoeducational group designed for Latin American caregivers of people with dementia.

Method: We assessed participants of a group developed at an outpatient unit for Alzheimer's disease. Interpretative phenomenological analysis was used to analyze differences in the caregivers' reports.

Results and Discussion: The participants, mostly spouses and daughters, presented moderate caregiver burden and different levels of awareness (aware, partially aware, or unaware). Disease awareness and the development of coping strategies were influenced by familism, religiosity, and duty. Becoming a caregiver was considered positive in some cases, due to religious convictions and beliefs related to the importance of caregiving. Caregiver unawareness may reflect an attempt to maintain integrity of the patient's identity.

Conclusions: Our data allow some comparisons across cultures, which may be valuable in assessing the influence of different psychosocial environments on the knowledge about dementia.

Keywords: Caregiver, dementia, awareness, intervention, qualitative study.
\end{abstract}

\section{Resumo}

Objetivo: Examinar diferenças na consciência da doença em participantes de um grupo psicoeducacional direcionado a cuidadores latino-americanos de pessoas com demência.

Método: Foram avaliados participantes de um grupo desenvolvido em um serviço para doença de Alzheimer. Utilizouse análise fenomenológica interpretativa para analisar diferenças nos relatos dos cuidadores.

Resultados e Discussão: Os participantes, em sua maioria esposas e filhas, apresentaram sobrecarga moderada e diferentes níveis de consciência da doença (preservada, parcial ou inexistente). A consciência da doença e o desenvolvimento de estratégias de enfrentamento foram influenciados pelo familismo, religiosidade e sentimento de obrigação moral. Tornar-se um cuidador também foi considerado positivo em alguns casos, por convicções religiosas e crenças relacionadas à importância do cuidar. A ausência de consciência pode refletir uma tentativa de manter a identidade do paciente.

Conclusão: Os dados permitem algumas comparações entre culturas, as quais podem ser valiosas para avaliar a influência de diferentes contextos psicossociais no conhecimento sobre a demência.

Descritores: Cuidador, demência, consciência da doença, intervenção, estudo qualitativo.

\footnotetext{
* Center for Alzheimer's Disease and Related Disorders, Institute of Psychiatry, Universidade Federal do Rio de Janeiro (UFRJ), Rio de Janeiro, RJ, Brazil. Financial support: Fundação de Amparo à Pesquisa do Estado do Rio de Janeiro (FAPERJ) (grant no. E-26/101.030/2007).

Submitted Jul 21 2012, accepted for publication Nov 14 2012. No conflicts of interest declared concerning the publication of this article.

Suggested citation: Santos RL, de Sousa MF, Ganem AC, Silva TV, Dourado MC. Cultural aspects in dementia: differences in the awareness of Brazilian caregivers. Trends Psychiatry Psychother. 2013;35(3):191-7.
} 


\section{Introduction}

Disease awareness is defined as the recognition of changes caused by deficits related to the disease process. ${ }^{1-3}$ It encompasses three dimensions: the ability to recognize a specific deficit; emotional response to difficulties; and the ability to understand the impact of impairment on activities of daily living. ${ }^{4}$ One of the approaches that have been taken to assess the level of patients' awareness consists of calculating the discrepancy between the patient's own account of the perceived difficulties and that of the patient's spouse or caregiver. In general, proxies tend to judge patient awareness to be lower than the patient's own judgement. ${ }^{5}$ As a result, first-person evaluations tend to be employed only as a supplement to third-person ratings provided by a caregiver. ${ }^{5}$ However, the caregiver may be more or less aware of the patient's behavioral and functional disorders.

Awareness has a complex nature and may also be subjectively determined. ${ }^{6}$ Regarding the caregiver's point of view, the subjective aspect of their awareness is influenced by how the clinical situation is presented, the degree of kindred and family ties, and caregiver factors such as time dedicated to the patient, burden of care, psychological health, and educational status. ${ }^{7}$

Caregiver awareness may also be determined by their motivations to provide care for people with dementia. Motivations can emerge from internal desires or beliefs but also from external pressures, playing a key role in determining both the social impact of the disease and the risks of stigmatization and discrimination. The cultural context can be considered an internal determinant that influences caregiving at multiple levels throughout the caregiving experience, mainly in regard to the meaning of being a caregiver. Consequently, it can be assumed that cultural justification for caregiving may reflect the cultural values and beliefs of a given group that can influence elder care provision and potentially increase or decrease emotional growth. It can also be assumed that motivations to provide care may partially determine the caregiver's awareness of the disease and thereby increase the risk of - or protect against - emotional distress and burden. ${ }^{8}$ It is necessary to consider that the caregiver's ability to recognize symptoms and the way how they interpret and act on them are central to redefining and reorganizing family relations and constitute an important and neglected aspect of the illness experience.

Contrasting the caregiving experience of different individuals and groups can enhance the theoretical understanding of this experience by distinguishing between universal elements and those mediated by the norms, expectations, or experiences of a given cultural group. ${ }^{9}$ Caregiver disease awareness may be also determined by cultural beliefs, significantly affecting the type of care offered and the sustainability of outcomes in patients with dementia.

In view of the above, and considering the likely implications of these considerations for clinical practice, this study aimed to explore differences in disease awareness and motivations to provide care among participants of a psychoeducational group designed for Latin American caregivers of people with dementia. Considering the complex relationship between awareness and cultural background, it seems appropriate to adopt an exploratory approach that considers how caregivers understand what is happening to them and how this experience, in turn, influences coping and adjustment.

\section{Method}

\section{Ethical issues}

This study was approved by the Ethics Committee of the Institute of Psychiatry at Universidade Federal do Rio de Janeiro (UFRJ), Rio de Janeiro, Brazil. All caregivers signed an informed consent form prior to the first group session.

\section{Design}

This was a qualitative study involving accounts of caregivers who participated in a psychoeducational group intervention.

Session transcripts were subjected to interpretative phenomenological analysis (IPA) ${ }^{10}$ in order to identify the key elements of the participants' understanding and experience. We chose to use IPA in this study because it has been described as particularly relevant for understanding subjective responses to illness. IPA is considered both phenomenological, because it aims to explore the participant's view on the topic being investigated, and interpretative, because it acknowledges that the participant's perceptions are elicited as part of a dynamic, interactive process in which the investigator's own beliefs and understandings also play a role as the investigator engages in interpretative activity to make sense of the participant's subjective world. ${ }^{10}$

All authors participated of the initial analysis, shared the same theoretical background, and were psychologists trained in psychoeducational interventions.

\section{Study participants}

This study included dementia caregivers ( $\mathrm{n}=$ 18 ; 2 males, 16 females) who were participants in a psychoeducational group developed at the outpatient 
unit of the Center for Alzheimer's Disease and Related Disorders, Institute of Psychiatry, UFRJ, Brazil.

Dementia patients ( $n=18 ; 7$ males, 11 females) had been diagnosed with Alzheimer's disease (AD) and vascular dementia (VD), and their mean age was 78.09 years. They presented a mean of 7.63 years of formal education and a mean of 5.18 years since the onset of the disease. The majority of patients scored 1 on the Clinical Dementia Rating (CDR), which means that they presented mild dementia. The CDR is a numeric scale used to quantify the severity of dementia. Each patient lived at home with his/ her family. All patients were on cholinesterase inhibitors.

\section{Intervention}

Selected participants were referred to the psychoeducational group following evaluation by a doctor. A baseline interview was conducted in which sociodemographic data were collected. Scales assessing caregiver burden and depression were also used. Finally, we collected data about the patient's premorbid history, history of disease, the context of family ties and relationships, and the main problems and difficulties related to the participant's daily activities as a caregiver.

The psychoeducational approach was used to offer information about the disease and emotional support to the caregivers. Caregivers had the opportunity to interact with one another, exchanging useful information and providing mutual support. The intervention followed the STARCaregivers model, ${ }^{11,12}$ in which an attempt is made to help caregivers identify, reduce, and manage the behavioral symptoms of people with dementia (these symptoms have been described as the main cause of caregiver burden, distress, and depression). The model follows five basic steps ${ }^{11,12}$ : 1) identifying behavioral symptoms that are very difficult to manage by describing them and detecting their frequency; 2) identifying precedents of each problem and their consequences; 3) tracing modifying strategies; 4) working on the communication between the caregiver and the patient with dementia; and 5) creating pleasurable events for caregiver and patient.

The intervention group consisted of a weekly, 90-minute session over 6 months. Sessions started with a warm-up to allow time for the participants to make comments or raise questions about the events that occurred in the past week in relation to their general state or to the care for the patients. Based on the caregivers' conversations, one specific topic was chosen as the main topic, with subsequent exchange of experiences, expressions of feelings related to the situations presented, and, finally, development of new strategies to solve the problems that had emerged in each experience. The group also held discussions following lectures with educational contents decided on by the participants in agreement with the group coordinator. Even though the presentations were educational, the group was motivated to talk about emotional issues raised by the topic discussed. The sessions were part of a closed program, i.e., new participants were not allowed to enter the group. All group sessions were transcribed by memory, immediately after the sessions, by the group coordinator. The coordinator was a psychologist with expertise in aging studies and trained in group techniques, with 4 years of experience in psychoeducational group interventions involving caregivers of patients with dementia.

\section{Data analysis}

Qualitative analysis was conducted so as to achieve a rigorous, comprehensive description of topics, by highlighting quotes to illustrate each topic and, where possible, use the participants' own words to label the topics. Initially, we read and revised each transcript a number of times to become familiar with the content. We took notes and compiled a summary list of key points, reproducing as much as possible the participants' words. This formed the basis for identifying topics emerging in each transcript, as key points were grouped together. At this stage, two investigators grouped key points independently, which permitted to compare the resulting data. Similarities and differences were examined, and differences were discussed until a consensus was reached. Closely related topics were grouped together under appropriate headings and clustered into sets. The result was a complete, hierarchically organized summary list of topics. Once the investigators had developed an agreed upon a final set of topics, all the transcripts were analyzed accordingly, and a full list of extracts related to each topic was compiled. Afterwards, we undertook the interpretative process of understanding how these extracts integrated with or challenged the current theory. The final list of key points is shown in Table 1.

Table 1 - Key topics and subtopics

\begin{tabular}{|c|c|}
\hline Topics & Subtopics \\
\hline Reasons to become a caregiver & Duty, feelings of gratitude, familism, and religiosity \\
\hline Awareness of dementia symptoms & $\begin{array}{l}\text { Difficulties in recognizing cognitive and functional impairment } \\
\text { Management of BPSD }\end{array}$ \\
\hline Awareness of patient's sense of identity & Maintenance of patient's past identity \\
\hline
\end{tabular}

BPSD = behavioral and psychological symptoms of dementia. 


\section{Results}

Caregivers' and patients' sociodemographic data are summarized in Table 2. All participants were family members, with a greater frequency of spouses and daughters living with the patient. There was a predominance of the female gender ( $n=9 ; 81.8 \%$ ), probably as a result of the cultural stigma according to which caregiving activities are the responsibility of women. ${ }^{13}$ Caregiver burden was considered moderate as assessed by the Zarit Burden Interview. ${ }^{14}$

Table 2 - Sociodemographic data

\begin{tabular}{|c|c|c|}
\hline & $\begin{array}{l}\text { Caregivers } \\
\text { Mean } \pm \text { SD }\end{array}$ & $\begin{array}{c}\text { Patients } \\
\text { Mean } \pm \text { SD }\end{array}$ \\
\hline Age $\quad 61.27 \pm 8.91$ & $78.09 \pm 10$ & \\
\hline Educational level & $11.63 \pm 3.2$ & $7.63 \pm 4.69$ \\
\hline Disease duration & - & $5.18 \pm 2.92$ \\
\hline \multirow[t]{2}{*}{ Zarit Burden Interview } & $31.18 \pm 13.7$ & \\
\hline & n (\%) & n (\%) \\
\hline \multicolumn{3}{|l|}{ Gender } \\
\hline Female & $16(88.9)$ & $11(61.1)$ \\
\hline Male 2 (11.1) & $7(38.9)$ & \\
\hline \multicolumn{3}{|l|}{ Kinship degree } \\
\hline Daughters & $10(55.6)$ & \\
\hline Spouses & $6(33.3)$ & \\
\hline Distant relatives & $2(11.1)$ & \\
\hline
\end{tabular}

$\mathrm{SD}=$ standard deviation.

\section{Disease awareness and reasons to become a caregiver}

The primary caregiver is usually chosen based on his/her relationship with the patient and with the whole family and also depending on personality characteristics, family issues, and sociocultural aspects. ${ }^{15}$

In caregiving, a person may be motivated to provide care for many reasons, e.g., feelings of duty and responsibility. Our data suggest that the main factor involved in the decision to become the main caregiver is a feeling of responsibility for the patient. According to the tradition spread throughout generations, especially in the Latin American culture, adult children are responsible for their parents when they get old. ${ }^{16}$ This is a natural process, in which the caregiver feels the opportunity to repay a past debt to the care recipient. Sometimes, becoming a caregiver is considered positive, due to stronger beliefs related to the importance of caregiving.

My mother and I weren't close when I found out she was in very bad conditions. She didn't eat properly, she didn't do her laundry, the house was dirty and her aggressive behavior was driving my stepfather crazy.
My stepfather is more than 90 years old and he is going blind. Besides, I'm her daughter and must take on this responsibility of being her caregiver. And you know what? After I started caring for her, we finally became closer again, and I feel good about it... (M.B., 65 years old)

Latin American people have distinct worldviews with regard to general assumptions about reality and values. Especially, familism is a core cultural value, referring to a strong commitment to the family as a system of support, learning, socialization, and assistance. ${ }^{9}$ The relationship between caregiving and perceived familial duty is common in Latin American societies. Family caregiving is considered a natural aspect of family life, even when the premorbid relationship has never been good. Familism may be a cultural aspect responsible for a deficit in caregiver awareness.

My mother was a very busy professor and didn't care so much about me. Our relationship has never been good, but it's my obligation to be her caregiver because I'm her daughter. However, I'm not sure if such an active and well educated person can really have Alzheimer's disease. (M.T., 61 years old)

Another important aspect to be considered is religiosity, ${ }^{16}$ a strong motivation for taking care of a disabled person. Latino caregivers tend to be more engaged in positive religious coping than their Caucasian counterparts, by finding a meaning in the caregiving process and perceiving lower degrees of caregiver burden and strain. ${ }^{17}$ We observed that positive religious coping helps in finding a meaning for caregiving tasks.

According to my religion, when you have to do something such as becoming a caregiver, it's because God sends you an opportunity to learn something. It's like a mission, you know? That's why you have to accept it with love. (S.C., 62 years old)

Conversely, religiosity can decrease caregiver awareness, as the carer may consider that dementia symptoms are caused by divine will. In these cases, instead of following medical prescriptions, the caregiver may think that dementia requires a spiritual treatment:

I spent too much time before I searched for a doctor and for the right treatment, because, when my wife started showing the first dementia symptoms, I thought she was disturbed by an evil force and needed a spiritual treatment. (J.S., 60 years old)

Latin American cultural values such as familism and religiosity can influence the reasons to become 
a caregiver; notwithstanding, the same values may arouse feelings of ambivalence. The caregiver may feel entrapped in a sort of moral obligation which pushes them to take on the responsibility of caregiving, even though they do not want to become the patient's main caregiver for several reasons. When caregivers feel this type of ambivalence, they may fail in finding a meaning for their caretaking activities, with the possible effects such as developing anxiety and depressive symptoms or even neglecting the care recipient.

\section{Disease awareness and dementia symptoms}

The majority of caregivers tend to have difficulties coping with the behavioral and psychological symptoms of dementia (BPSD). ${ }^{18}$ It has been reported that symptoms such as delusions, agitation/aggression, anxiety, irritability/lability, and dysphoria/depression are strongly associated with higher caregiver burden. ${ }^{19}$ These symptoms may arouse negative feelings, such as entrapment, shame, or guilt, which may lead to higher levels of depression and physical symptoms. ${ }^{20}$

He's started thinking that the mirror is one of his colleagues from the army, and he talks with this imaginary friend. His wife got desperate, and she has decided to take the mirror out of their bedroom... (L.B., 60 years old)

Caregivers have difficulties distinguishing between dementia symptoms and the patient's personality.

I never know when my mother's behavior is motivated by her personality or by the symptoms of dementia. Sometimes I think she wants to call my attention and disturb me. She doesn't accept any kind of help, but she's always been bossy throughout all her life. What's from the disease and what comes from my mother herself? (M.T., 61 years old)

\section{Awareness of patient's sense of identity}

Caregivers often feel confronted with cognitive and functional impairment, facing the idea that their family members are losing their sense of identity. This may result in a loss of identity of the caregivers themselves.

When someone asks my wife's full name, she mentions the family name she used to have when she was single. One day I was driving, she looked at me and asked who I was. I told her I was her husband, but she said she wasn't married. I know that it is a consequence of the disease, but I feel sad that nowadays I am not indispensable to my wife anymore. (C.A., 72 years old)
Also, caregivers tend to observe whether their relatives with dementia have a certain level of awareness of the disease or not.

She has been a professor, she has read a lot of books, and her house has a huge library. When someone talks to her, she tries to show she has a wide vocabulary and she is still that woman from the past. I do not think she is aware of her deficits. She always says that she is okay. (M.T., 61 years old)

Moreover, caregivers may be either aware, partially aware, or unaware of the disease. ${ }^{2,4}$ In fact, caregiver unawareness may be an attempt to maintain the integrity of the patient's identity. When confronted with the diagnosis of dementia and the various losses provoked by the disease, the family caregiver may experience an increased burden caused by anticipatory grief. ${ }^{21}$ Moreover, the caregiver may deny the disease and loss of roles, increasing their emotional distance with the patient.

My mother is forgetful, but she can get a bus by herself and go to my sister's house in another city. I just have to tell the bus driver she has dementia and give him emergency phone numbers. However, I feel worried: the last time, the driver had to stop the bus, and she got agitated. A passenger called me, my mother got calmer and continued the trip. Well, I think it won't happen anymore. My mother has some memory problems, but she still does many things. It was just a moment of confusion. (E.B., 56 years old)

\section{Discussion}

We explored differences in awareness among dementia caregivers considering some cultural aspects that may have influenced the information participants received about the disease and the development of their ways of coping. The three overarching topics that emerged from the participants' accounts reflected a tension between acknowledging the responsibility and the stress of caring for the dementia patient and wanting to maintain one's sense of identity.

Caregiving may be considered as having both positive and negative aspects and a wide range of outcomes. The motivation to provide care is determined by both cultural and individual aspects and may influence disease awareness, depending on whether caregivers are able to identify negative or positive aspects related to the activities of caring.

Social representations of family and religion are additional cultural aspects that may influence caregiver 
awareness. For instance, tradition and spirituality, subtopics of reasons to become a caregiver, are considered social norms, especially in Latin American countries. It should be observed that the motivations described by caregivers are based on a belief that legitimizes this symbolic universe. This may stem from religious beliefs and practices common in Latin American people (e.g., "for it is in giving that we receive" and the practice of making promises). The idea constantly expressed as "bearing the cross that God lays on your shoulders" leads to the question of divine punishment (crime and punishment), representing the risk that one incurs by not complying with God's commands. Faith often appears as a source of support to face difficulties and suffering, offering strength to overcome them. Even though our Latino group tended to consider caregiving as a meaningful role, due to their religiosity and their sense of gratitude towards the care recipient, we also observed that they failed in improving their own mental health when compared with European American caregivers. ${ }^{9}$ In this sense, the present findings may help develop specific interventions for different groups, according to cultural aspects.

Also, the group sessions showed that family caregiving may be primarily motivated by affection, altruism, social norms of responsibility, and even egotistic motivations. ${ }^{22}$ Ambivalent feelings were frequently present and were inherent to the caregiving task, manifested by the counterpoint of physical and emotional exhaustion on the one hand - "being on the verge of a breakdown" - and satisfaction about doing one's duty on the other. Meaning is conceptualized here as a mediator of the stress process, as "management of the meaning of the situation," and is viewed as a coping mechanism. ${ }^{23}$ Failure to find meaning may potentially have negative outcomes for both caregiver and care recipient. The caregiver may experience feelings of despair or hopelessness, which could in turn impact on the care recipient's well-being. ${ }^{24}$

Even though the participants' awareness of the disease was evident, this was often partial, as there was considerable confusion in some domains, especially with regard to BPSD and maintenance of the patients' sense of identity. As caregivers witness the patient's successive losses, they may feel that they themselves are losing their identities too.

Therelationship between the caregivers' understandings of dementia and their daily experience was reflected in the topics of awareness of dementia symptoms and awareness of the patient's sense of identity. These topics encapsulate a range of dilemmas that our caregivers faced as they developed an understanding of dementia, considered its implications for the patients' sense of identity, and negotiated a range of social situations and relationships with them. Cultural stereotypes associated with aging and coexisting medical problems also seem to have influenced the concepts of caregivers. Prior information and biomedical concepts about dementia supported the caregivers' interpretations about the disease, thus influencing their reactions, the problem itself, and intrafamily arrangements.

Our group participants showed moderate burden of care. Even though the determinants of caregiver burden are well known, ${ }^{8}$ cultural background and the resulting attitudes toward the disease may also partially determine the caregiver's investment in the care of their loving ones and thus increase the burden of care. A recent study ${ }^{8}$ has shown a link between negative attitudes towards the disease and feelings of burden experienced by caregivers of $A D$ patients.

The psychoeducational intervention that we found relevant to test involved three basic techniques: information provision, role clarification, and belief clarifications. In the first technique, group participants were provided with presentations, readings, in a workshop environment, welcoming questions about the disease and about its effects on the care recipient's daily life. Role clarification, in turn, emphasized the caregiver's role, which includes assuring security and comfort to the care recipient and helping him/ her find joyful activities. This type of intervention helps caregivers understand that their role is not associated with rehabilitation or retarding the course of the disease. Finally, psychoeducational interventions could also provide belief clarifications, in which caregivers are stimulated to view their situation with some distance, developing strategies to deal with immediate and recurrent caregiving situations and, as a result, becoming more aware of the emotional impact of their actions on the patient. Ideally, a psychoeducational group intervention should involve miscellaneous techniques, helping caregivers become more aware of the disease and of their role in the relationship with the patient, as well as offering them a suitable environment for the exposure of feelings related to the caretaking experience.

A recent systematic review ${ }^{25}$ has investigated a model based on miscellaneous techniques. In comparison with groups which provide only information about the disease, the ones based on multiple components offer better results in decreasing caregiver burden as well as depressive and anxiety symptoms. Therefore, a mixture of the techniques above seems to deserve investigation as a unique psychoeducational group intervention method, based on rigorous, structured steps developed according to the participants' cultural characteristics.

Some limitations of our study should be mentioned. First, we had a small sample of caregivers, with homogeneous sociodemographic characteristics, including a majority of women (spouses or daughters). Conversely, our sample was quite heterogeneous in terms of level of burden, 
depressive and anxiety symptoms. On the one hand, we could argue that this characteristic was beneficial for the development of the group dynamics, as caregivers had the opportunity to share experiences among themselves. On the other hand, however, if methodological issues are taken into consideration, it becomes evident that a bigger, randomized sample would be better.

Also, the caregivers included in the study were demonstrably seeking help: they were referred to the group after medical evaluation, and all of them were willing to contribute to their patients' treatment and to be a part of the psychoeducational intervention. Therefore, our results cannot be considered representative of the effects of the same type of intervention applied to caregivers who are not help-seekers. Finally, we are unable to objectively measure to which extent the caregivers participating in the treatment group acquired new knowledge or appropriate skills from the practice acquired with daily activities with the patients.

A clinical implication of our results is the important role and the value of fully involving the caregiver in psychoeducational interventions, providing information about the condition, its prognosis, and ways of coping with it, all of which may be important for improving awareness. ${ }^{25}$ Because it is necessary to identify which coping styles are affected by cultural differences, psychoeducational interventions with caregivers should include culturally-bound positive coping techniques, i.e., an exploratory approach that considers the cultural background that influences the way how caregivers understand what is happening to them and how this, in turn, influences coping and adjustment.

\section{References}

1.Zanetti O, Vallotti B, Frisoni GB, Geroldi C, Bianchetti $A$, Pasqualetti $P$, et al. Insight in dementia: when does it occur? Evidence for a nonlinear relationship between insight and cognitive status. J Gerontol B Psychol Sci Soc Sci. 1999;54:100-6.

2. Dourado M, Laks J, Rocha M, Soares C, Leibing A, Engelhardt E. Consciência da doença na demência: resultados preliminares em pacientes com doença de Alzheimer leve e moderada. Arq Neuropsiquiatr. 2005;63:114-118.

3. de Sousa MF, Santos RL, Brasil D, Dourado M. Consciência da doença na demência do tipo Alzheimer: uma revisão sistemática de estudos Iongitudinais. J Bras Psiquiatr. 2011;60:50-56.

4. Dourado M, Marinho V, Soares C, Engelhardt E, Laks J. Awareness of disease in Alzheimer's dementia: description of a mild to moderate sample of patient and caregiver dyads in Brazil. Int Psychogeriatr. 2007;19:733-44.

5. Trigg R, Wats $S$, Jones $R$, Tod A. Predictors of quality of life ratings from persons with dementia: the role of insight. Int J Geriatr Psychiatry. 2011;26:83-91.

6. Clare L, Wilson B, Carter G, Roth I, Hodges JR. Assessing awareness in early-stage Alzheimer's disease: Development and piloting of the Memory Awareness Rating Scale. Neuropsychol Rehabil. 2002;12:341-62.
7. Onor ML, Trevisiol M, Negro C, Aguglia E. Different perception of cognitive impairment, behavioral disturbances, and functional disabilities between persons with mild cognitive impairment and mild Alzheimer's disease and their caregivers. Am J Alzheimers Dis Other Demen. 2006;21:333-8.

8. Zawadzki L, Mondon K, Peru N, Hommet C, Constans T, Gaillard $P$, et al. Attitudes towards Alzheimer's disease as a risk factor for caregiver burden. Int Psychogeriatr. 2011;23:1451-61.

9. McCallum TJ, Sorocco KH, Fritsch T. Mental health and diurnal salivary cortisol patterns among African American and European American female dementia family caregivers. Am J Geriatr Psychiatry. 2006;14:684-93.

10. Smith J, Jarman M, Osborn M. Doing interpretative phenomenological analysis. In: Murray $M$, Chamberlain K, editors. Qualitative health psychology: theories and methods. London: Sage Publications; 1999. p. 218-240.

11. Logsdon R, McCurry S, Teri L. STAR-Caregivers: a community-based approach for teaching family caregivers to use behavioral strategies to reduce affective disturbances in persons with dementia. Alzheimers Care Q. 2005;6:146-56.

12. Teri L, McCurry SM, Logsdon R, Gibbons LE. Training community consultants to help family members to improve dementia care: a randomized controlled trial. Gerontologist. 2005;45:802-11.

13. Karsch UM. Idosos dependentes: famílias e cuidadores. Cad Saude Publica. 2003;19:861-6.

14. Zarit SH, Orr NK, Zarit JM. The hidden victims of Alzheimer's disease: families under stress. New York: New York University Press. 1985.

15. Gaugler JE, Zarit SH, Pearlin LI. The onset of dementia caregiving and its longitudinal implications. Psychol Aging. 2003; 18:171-80.

16. Gómez M. Estar ahí, al cuidado de un paciente con demencia. Invest Educ Enferm. 2007;25:60-71.

17. Rabinowitz YG, Hartlaub MG, Saenz EC, Thompson LW, Gallagher-Thompson D. Is religious coping associated with cumulative health risk? An examination of religious coping styles and health behavior patterns in Alzheimer's dementia caregivers. J Relig Health. 2010;49:498-512.

18. Melo G, Maroco J, de Mendonça A. Influence of personality on caregiver's burden, depression and distress related to the BPSD. Int J Geriatr Psychiatry. 2011;26:1275-82.

19. Huang SS, Lee MC, Liao YC, Wang WF, Lai TJ. Caregiver burden associated with behavioral and psychological symptoms of dementia (BPSD) in Taiwanese elderly. Arch Gerontol Geriatr. 2012;55:55-9.

20. Martin Y, Gilbert P, McEwan K, Irons C. The relation of entrapment, shame and guilt to depression, in carers of people with dementia. Aging Ment Health. 2006;10:101-6.

21. Holley CK, Mast BT. The impact of anticipatory grief on caregiver burden on dementia caregivers. Gerontologist. 2009;49:388-96.

22. Doty P. Family care of the elderly: the role of public policy. Milbank Q. 1986;64:34-75.

23. Pearlin LI, Mullan JT, Semple SJ, Skaff MM. Caregiving and the stress process: an overview of concepts and their measures. Gerontologist. 1990; 30:583-94.

24. Quinn C, Clare L, Woods RT. The impact of motivations and meanings on the wellbeing of caregivers of people with dementia: a systematic review. Int Psychogeriatr. 2010;22:43-55.

25.Santos RL, de Sousa MF, Brasil D, Dourado M. Intervenções de grupo para sobrecarga de cuidadores de pacientes com demência: uma revisão sistemática. Rev Psiq Clin. 2011;38:161-7.

\section{Correspondence}

Raquel Luiza Santos

Rua Constança Barbosa, 140/504, Meier

20735-090 - Rio de Janeiro, RJ - Brazil

Tel./Fax: +55-21-7929-1133

E-mail: raquelluizasantos@yahoo.com.br 